\title{
PERFORMANCES DA MEMÓRIA, PERFORMANCES DA HISTÓRIA: CONSIDERAÇÕES A PARTIR DO PROCESSO CRIATIVO DE SOMAMNEMOSIS
}

\author{
Thaise Luciane Nardim \\ Professora Assistente na Universidade Federal do Tocantins \\ Mestre em Artes Cênicas pela Universidade Estadual de Campinas \\ E-mail: thaise.nardim@gmail.com
}

Neste texto, orientada pelo chamado método da cartografia, narro e analiso, em primeira pessoa, o processo criativo de uma obra de arte da performance que teve como disparador o debate entre noções de memória e história, especialmente no que tange à constituição de uma história da arte da performance. As conclusões apontam para o exercício de uma memória encarnada dessa arte.

Palavras-chave

Arte da Performance. História da Arte da Performance. Memória. Mnemotécnica. Processo Criativo.
In this paper, oriented by the so called cartographyc method, I narrate and analyze in first person the creative process of a work of performance art that was to trigger discussion among notions of memory and history, especially regarding the establishment of a history of performance art. The findings points to the exercise of an embodied history of this form of art.

Keywords

Performance Art. History of Performance Art. Memory. Mnemotechnics. Creative Process. 
"A ética da manutenção da vida na performance passa pelo viés do corpo"

Christina Fornaciari

Neste texto, busco dar a ver o percurso entre fazeres e reflexões que percorri ao criar e apresentar a performance Somamnemosis ou a história da arte da performance do corpo ao corpo, tendo em vista minha atuação concomitante como artista da performance e pesquisadora da teoria dessas práticas, especialmente orientada a criar trabalhos artísticos que interseccionem tais campos de atuação. Tematicamente, a obra em questão pretendeu tensionar entendimentos de memórias na e da arte da performance, em especial em suas relações de co-engendramento no estabelecimento de narrativas acerca dessa forma de arte relativamente jovem. No momento em que esse processo criativo transcorreu, tendo sido disparado pela convocatória de um comitê curatorial, a memória e suas implicações nas artes da cena eram temas de estudo de um curso de pós-graduação do qual eu vinha participando como estudante, o que, como busco demonstrar a seguir, favoreceu o caráter teorico-prático e autoreflexivo do processo. Entendo que Somamnemosis foi uma experiência forjada por mim como estratégia para colocar-me em relação de fricção com esse tema e poder alcançar estratos da reflexão que eu teria dificuldade em conceber sem o auxílio da corporificação do problema.

A composição e presentação de projetos de arte da performance, com vistas ao estudo e investigação em ato de um determinado campo, é um procedimento de que venho lançando mão sistematicamente nos últimos anos, sob a regência ou inspiração do chamado método cartográfico, conforme a elabora- ção de Passos, Kastrup e Escóssia (2009) e, quando no contexto da prática docente, com o auxílio da metodologia a/r/tográfica (DIAS E IRWIN, 2014). É sob tal orientação que recorro, aqui, à narrativa em primeira pessoa, retomando o apelo cartográfico à "política da narratividade", (PASSOS, KASTRUP E ESCÓSSIA, 2009) bem como à inserção de trechos de textos não acadêmicos, de minha própria autoria ou de outrem, que me auxiliarão a reconstruir o processo criativo em questão. No corpo do ensaio, tais trechos, quando redigidos por mim, seguem identificados entre aspas e sem referência a autor e data, em sua conclusão.

Iniciando as reflexões que indicarão um aprofundamento em Somamnemosis, questiono: dado o estabelecimento relativamente recente da prática em arte da performance enquanto campo pretensamente autônomo nos circuitos artísticos, quais os limites para afirmarmos uma história da arte da performance? Podemos já agora falar nesses termos? O performador e investigador Fernando Ribeiro propõe-nos que não poderíamos efetivamente afirmá-la - ou ainda, não exatamente ou não "no sentido grande de História. Mas, como Paul Veyne afirma, há uma história comparada, ou seja, uma história da performance dentro de uma história da arte, que se inscreve no que pode ser chamado de A História" (RIBEI$\mathrm{RO}, 2009)$. A partir dessa ideia, sugiro como questão a acompanhar a leitura deste trabaIho: dada a natureza da arte da performance, não seria apropriado, por parte do performador, negar essa sua História incipiente e parcial defendendo, em lugar dela, uma memória (encarnada, como o são as memórias) da arte da performance? A história, assim como memória, são práticas tributárias da fundação da linguagem - a ambas a existência só se faz 
possível pela inscrição em regimes linguísticos - e assim sendo, o performador, constituidor de linguagem em vivo por excelência, não poderá, através de sua obra, produzir resistência ao ponto de vista emitido pelo historiador, negando a necessidade de uma interpretação que reifique uma periodização, uma cronologia, um grupo, uma região ou um modo de fazer como representativos de uma prática por natureza múltipla, que não cessa de negar seu fechamento em um conceito?

O projeto de Somamnemosis foi redigido com fundamento nesses questionamentos, que vinham sendo levantados no contexto da disciplina. Ao produzi-lo, eu visava atender à convocatória de participação no evento Perfor5 - quinto Fórum da Associação Brasil Performance. Fundada em 2008, a partir da iniciativa de um coletivo de performers sediados em São Paulo/SP, dentre os quais alguns veteranos da arte da performance brasileira, como Lúcio Agra e Otávio Donasci, além de outros artistas ligados à produção de Renato Cohen como as performers do grupo MediaKA, Samira Br e Ana Goldstein, essa associação atua na defesa daquilo que concebe como os direitos dos artistas da performance, buscando garantir, entre outras requisições, que os editais de apoio e fomento à arte reservem um espaço especifico para este campo, considerada sua autonomia. O fórum, realizado desde 2009, configura-se como um espaço de encontro entre os artistas associados e também como um momento de debates, formação e construção de conhecimento em arte da performance. Eu havia participado como ouvinte externa não-associada do Perfor1, em 2009; como artista convidada, com performance à distância via internet, no Perfor4, em 2013, quando realizei, a partir de Palmas/TO, e com o uso da plataforma de transmissão de captação de vídeo em tempo real Livestream, uma ação da série Ficando Invisível; e, finalmente, em 2014, quando optei por associar-me e submeti um projeto para participação como artista selecionada.

O Perfor5 teve como tema "Quando?", propondo um debate sobre a memória e o arquivo no campo da arte da performance. $O$ texto de chamada para a submissão de propostas de trabalho dizia:

Agora é a memória. Percebemos hoje, mais do que nunca, a necessidade de compreendermos a nossa relação com a história já que estamos rodeados de uma quantidade enorme de novos mecanismos de registro e difusão de informação. Numa arte fugaz como a performance, a permanência torna-se uma questão em vista das pressões mercadológicas e do próprio entendimento do que significa militar em uma forma de arte centralizada no efêmero. Que consequências isto pode ter para a arte de ação? Como se pode dialogar com os mecanismos de controle para que não capturem aquilo que funciona na "velocidade do escape"? O Perfor5 será uma ocasião para performar e pensar estes problemas. Para interrogarmo-nos sobre o quando (ASSOCIAÇÃO BRASIL PERFORMANCE, 2014)

Esta declaração de princípios do evento abre um primeiro campo para visualizarmos as questões da memória que irão fundamentar o projeto, a apresentação e o desenvolvimento da obra e nas relações que irão orbitar em seu entorno. A partir do cotejo entre o título do evento - Quando, um vernáculo que, na norma padrão da língua portuguesa, funciona como advérbio de tempo - e a primeira frase da passagem - Agora é a memória - interpretei inicialmente que o evento propunha uma acepção da memória como função temporal, isto é, a 
memória como algo que indica para um quando, para um recorte de tempo, ainda que esse tempo seja o agora, o instante imediato - sem mediação, em que o arquivo faz-se impossível. Adiante, o texto aponta para mecanismos de registro e difusão, como técnicas às quais a produção de memória estaria subordinada, dado que estes possibilitariam a permanência de uma forma de arte considerada fugaz - permanência que se apresenta quase como um sinônimo de memória e dos mecanismos de controle que capturariam a velocidade da arte da ação, captura que ao evento parece soar negativa, dada a opção pelos termos. $O$ texto ainda denota a compreensão de todas essas ações produtoras de memória-tempo dos mecanismos de registros como questões problemáticas, visto que são apresentados em oposição à efemeridade, à fugacidade e à velocidade de escape supostamente próprias ou mesmo fundantes da arte da performance.

Todas as indicações apontam para uma compreensão da memória enquanto retenção, ideia que perpassa o entendimento do senso comum, cujo estabelecimento deve-se, em especial, à compartimentação operada pela ciência moderna, a partir de herança antiga e medieval, entre uma faculdade humana que rememora - a própria memória - e outra faculdade que cria, a imaginação (LEONARDELLI, 2008, 11). Considerando, porém, que o objeto sobre o qual nos debruçamos é um fazer artístico que se funda junto à contemporaneidade, proponho que problematizemos a memória também junto aos pensadores contemporâneos desse atributo que, ainda a partir de fontes antigas e modernas, propuseram uma memória de natureza dinâmica e ativa, como "recriação do vivido em circuitos permeáveis" (idem, 105), que produz conhecimento e não apenas retém informação, tal qual propõe-se que a arte da performance produza presença e um presente diferenciado. Uma tal abordagem seria capaz de conduzir-nos à compreensão de que os registros, antes que problemas de memória ocasionados por seu caráter retentivo - ainda que problemas políticos como os interpretará a militância anti-institucional - sejam relatos "dos processos de des-territorialização e re-adensamento" (idem, 145) da prática de uma linguagem também re-criativa, tão expandida e expansível quanto os limites dos fazeres humanos.

Outras pistas sobre um entendimento de memória que se apresentou frente à elaboração de Somamnemosis advêm do campo de influência da instituição artística que recebia o evento. O Perfor5 foi acolhido pelo projeto curatorial MaPa - Memória Paço das Artes, coordenado pela curadora Priscila Arantes e desenvolvido no bojo daquela instituição a partir de seu acervo histórico. Compunha-se, tal projeto, por uma exposição e o lançamento de uma plataforma digital que, de acordo com o Paço,

reúne todos os artistas, críticos, curadores e membros do júri, que passaram pela Temporada de Projetos desde sua criação em 1996. A plataforma é composta por imagens, textos críticos, entrevistas e vídeos (produzidos especialmente para o projeto, desde o início de 2014). Além disso, dá ao visitante a possibilidade de traçar relações entre estes artistas, críticos, curadores e jurados. (PAÇO DAS ARTES, 2014).

De acordo com essa declaração, o que seria a memória do Paço das Artes constituise pelos documentos que atestam os fatos que compõem a sua história, transformados a partir da eleição curatorial, que seleciona o 
que é exposto e o que é silenciado - em fatos históricos que denotarão a visão que a instituição quer lançar de si mesma.

Frente a essa leitura de memória que o evento propunha, de acordo com minha interpretação, aos possíveis colaboradores e espectadores, julguei ter encontrado nele uma oportunidade valorosa para pôr-me a refletir sobre as questões da memória em construção e acerca da arte da performance, bem como de elaborar, pela composição poética, aquilo que vinha questionando acerca da história dessa arte no contexto da pós-graduação. Pareceu-me interessante posicionar-me conceitualmente dentro do evento através de um exercício reflexivo em arte da performance, colaborando com o debate ao propor uma obra que se pretenderia fundada naqueles conceitos de memória que não integravam a construção conceitual do Fórum que, ao menos, não eram revelados em seu texto de posicionamento. Em especial, interessava-me pensar a memória como atributo dinâmico e criativo, ao mesmo tempo que problematizar os modos definitivos e retentivos de contar a história da arte da performance. A segunda parcela do título do trabalho, "a história da arte da performance do corpo ao corpo", surgiu já neste momento, disparada pelo título do livro de Roselee Goldberg, "Arte da performance: do futurismo ao presente", em que a pesquisadora estadunidense apresenta uma série de trabalhos do campo da arte da performance, ocidentais e do hemisfério norte que, segundo a perspectiva da autora, comporiam o leque de referências necessário para compreenderse este fazer no decorrer do período eleito, livro que é uma referência incontornável quando se pensa a história da arte da performance no contexto brasileiro, dado que foi o primeiro volume sobre o tema a ser editado em nosso país. Graças às leituras anteriores que eu havia realizado dessa obra, com uma perspectiva crítica, pareceu-me importante marcar o distanciamento de uma abordagem cronológica, linear, autoral e orientada por uma natureza de conhecimento discursivo e intelectivo, enquanto eu intencionava propor o suporte corpo de modo não linear, buscando produção de um conhecimento experiencial e "presentacional". Com isso, elaborei a seguinte preposição: "a performance brinca com a mnemotécnica antiga, consagrada nos textos dos artistas da retórica Cícero e Quintiliano, bem como no texto anônimo Ad Herrenium, para abrir brechas de reflexão sobre como lembramos a história da arte da performance. Como sabemos, esses pensadores da memória clássica recorriam a marcações espaciais, em especial as arquitetônicas, para que pudessem recordar dos argumentos e estratégias a utilizar em seus discursos, associando determinada ideia a um local (ou a uma imagem, e, então, associando essa imagem ao local), ao qual se pudesse retornar mentalmente em momento posterior, a fim de lembrar-se com facilidade de numerosas ideias, quando da enunciação".

A proposta era compor um palácio da memória da arte da performance, recorrendo não ao espaço arquitetônico, mas a um mapa da anatomia do corpo humano. Assim, o trabalho iniciaria com a disponibilização da ilustração de um corpo humano em tamanho real, junto ao qual haveria canetas e papéis. Os interessados deveriam relatar, por escrito, performances que viram, fizeram ou da quais ouviram falar, depositar esse papel em uma urna e marcar, na ilustração do corpo, um órgão em que essa performance ficaria localizada. O material deveria ser disponibilizado durante 
todo o primeiro dia do evento, recolhendo tantas memórias-performances quantas fossem possíveis. A partir das descrições recolhidas, no último dia do evento, a performer empreenderia uma ação em que deveria lembrar-se de todas as performances indicadas, narrando por completo as descrições apresentadas, recorrendo à imagem corporal para fazê-lo e assumindo as implicações corporais que daí advieriam. Uma questão que permaneceu em aberto nesta proposição é que o modelo espacial utilizado pelos retóricos privilegiava a recordação de discursos lógicos, de narrativa encadeada, com início, meio e fim. Entretanto, o mapa corporal não é necessariamente sequencial como pode ser o mapa da cidade. Entre diversos resultados, isso pode fazer com que as performances sejam trazidas à memória por uma ordem do momento ou do encontro, ou ainda por uma ordem coreográfica que advém quando o corpo encontra a ação, e não por sua ordem cronológica, possibilitando a descoberta de diferentes modos de narrar o trecho histórico que ali se compõe e abrindo caminhos para a reflexão sobre como os livros vêm contando essa relativamente jovem história.

A arte da memória e as imagens agentes em performance

Apesar da intenção de propor uma problematização da memória e da história da arte da performance ancorada na contemporaneidade, recorri às mais antigas técnicas de mnemônica como matéria a maleabilizar, pela via da obra, esperando que essa opção auxiliasse na remissão a uma ideia generalizante de memória. Isto porque, conforme adverte Frances Yates ainda no início de seu livro $A$ arte da memória (2007), as técnicas de memorização desenvolvidas pelos gregos antigos muitas vezes confundem-se com a própria ideia de uma arte da memória. Entretanto, como prossegue a mesma autora, ainda que as técnicas de memorização constituam a base factual das investigações sobre a arte da memória em todos os tempos, tais estudos deverão lograr ir além da história dessas técnicas.

Embora a invenção das técnicas mnemônicas seja atribuída aos gregos antigos, ainda segundo a leitura de Yates, é no texto latino Ad Hereniumm que a maior parte dos estudiosos baseou-se para descortinar tais práticas para a História. Ad Hereniumm teria sido redigido por um desconhecido mestre de retórica romano, aproximadamente no período de 86-82 a.C. e era destinado aos seus alunos de arte retórica. Iniciando a exploração sobre o tema da memória no trabalho do retórico, o autor nos diz:

XVI. Agora voltemo-nos ao tesouro das invenções, à custódia de todas as partes da retórica, à memória. [...] Há, então, dois tipos de memória: uma natural e outra artificial. A memória natural é aquela que está inserida em nossas mentes, nascida simultaneamente com o pensamento; a memória artificial é aquela que é fortalecida e conduzida pelo ensinamento da razão. Mas, como em todas as coisas, a excelência da natureza, muitas vezes, é superada pela doutrina, a arte, da mesma forma, reforça e desenvolve as vantagens da natureza, proveitosamente, conserva-as e as amplia pelas razões da doutrina. A memória natural, se a pessoa for dotada com uma excepcional, é, muitas vezes, como esta memória artificial, e esta memória artificial, por sua vez, fixa e aperfeiçoa as qualidades naturais pela arte do método (apud ALMEIDA, 1999, 67).

A partir da distinção entre duas me- 
mórias - uma natural, outra artificial - o autor proporá os recursos técnicos para o que ele chamou de fortalecimento da memória artificial. Yates descreve essa apresentação dos fundamentos da técnica do seguinte modo:

A memória artificial fundamenta-se em lugares e imagens (...), definição básica que será seguida no transcorrer do tempo. Um locus é um lugar facilmente apreendido pela memória, como uma casa, um intercolúnio, um canto, um arco, etc. Imagens são formas, signos distintivos, símbolos (...) daquilo que queremos nos lembrar. Por exemplo, se queremos nos lembrar de um gênero de um cavalo, de um leão, uma águia, precisamos colocar suas imagens em lugares (loci) definidos. (YATES, 2007, 23)

Segue-se a essa introdução uma diversidade de especificações e recomendações que nos revelam pormenores da atuação dos retóricos da antiguidade e de seus continuadores. Entretanto, para os limites de nossa reflexão, interessa-nos destacar que a técnica mnemônica que Somamnemosis se propôs a reler é fundada na associação entre imagens de uma ideia e espaços ou lugares, o que me propus a aproximar da arte da performance deslocando a associação dos loci arquitetônicos ou urbanos para loci do soma, corporais. Poderia a proposição de um deslocamento material nessa operação técnica proporcionar algum deslocamento conceitual no que concerne ao fazer memória e ao fazer história em arte da performance?

Durante o período entre o envio da proposta e sua realização, entretanto, não pude deixar de observar as fragilidades do projeto. Tal como diagnosticou a organização do evento - que, a despeito disso, aprovou-o - não se sabia exatamente o que eu faria no dia da apresentação, o que poderia gerar transtornos de ordem técnica. Além disso, embora conhecesse a técnica mnemônica que servia de referência, a transposição do referente à proposta não era consistente, pois deveria tratar-se de uma recriação, ou uma transcriação e não uma tradução, apenas. Questionei-me se o que propunha seria uma geografia da arte da performance e não uma historiografia alternativa. Entretanto, sabendo que é justamente a metáfora geográfica que fundamenta as reflexões de Deleuze e Guattari (1995-1997), no sentido inclusive da proposição de uma abordagem não hierárquica do saber, optei por seguir naquela orientação. A data aproximou-se e, tendo entendido que a coleta das performances por papel seria tecnicamente problemática, optei por coletar pessoalmente, com os frequentadores do evento, suas respostas. Assim, formulei a pergunta: "se você pudesse escolher uma performance, qualquer uma - que você fez, viu ou ouviu falar - para integrar um livro definitivo sobre a história da arte da performance, qual obra você acredita que não poderia deixar de constar?".

Planejei utilizar, depois da coleta das respostas, um período da tarde anterior à apresentação para decorar as informações, localizando cada uma delas, por associação de imagens, em uma parte do meu corpo. Assim, na apresentação eu iria, por recorrer às localidades corporais memorizadas, relatar aos espectadores as respostas coletadas. Com isso, a partir da abertura exata do evento, dei início às conversas com as pessoas que estavam ali para ver ou para realizar performances. Após um breve período de coleta, em debate com alguns amigos, entendemos que o trecho "fez, viu ou ouviu falar" poderia direcionar as respostas para performances de pessoas próxi- 
mas aos respondentes. Buscando manter a questão tão neutra quanto possível em relação ao tempo, localização e à inserção no sistema de identificação da arte por parte do artista escolhido, reformulei a pergunta para: "se fosse escrito um livro da história da arte da performance - um livro definitivo, completo, de toda a história da arte da performance - qual obra você acredita que não poderia deixar de constar?".

Ao iniciar as conversas, também postei em meu perfil do Facebook, bem como no perfil da Associação Brasil Performance, a mesma pergunta. No post, adicionei o pedido para que o respondente, se quisesse, relatasse também os motivos que o levavam àquela escolha, pedido que, na coleta pessoal, eu acabava por fazer no desenvolvimento da conversa. Entre as 19 horas da sexta-feira e as 13 horas do domingo, coletei, entre conversa presencial e respostas virtuais, 52 respostas. $\mathrm{Na}$ sequência, optei por memorizar blocos de informações compostos pelas características da pessoa respondente, o programa da performance escolhida e o motivo alegado para a escolha. No domingo, após as 13 horas, estudei os trabalhos para certificar-me de que conhecia seus programas e pedi a uma amiga que me fizesse uma prova oral sobre os grupos de dados. Desenhei um corpo humano sobre o papel e, lendo cada grupo de informações, fui associando-os a uma parte desse desenho que representava o meu próprio corpo. Segui utilizando os critérios que me ocorreram, sem estabelecê-los previamente, conforme exemplificado a seguir:

- o grupo da performance Pancake, de Márcia X, foi localizado no topo da testa, onde caía o leite condensado que a artista derramava (primeira imagem que me surge ao pensar nesta obra);

- o grupo de Paradox of Praxis, de Francis Allis, foi localizado no joelho, já que ao buscar uma parte do corpo para localizar este grupo me ocorreu que os joelhos do artista teriam sido muito exigidos durante o percurso, graças à posição que ele teve de assumir para empurrar o bloco de gelo até seu completo derretimento pela Cidade do México;

- o grupo da performance de uma bataIha de drag queens, no reality show RuPauls Drag Race, foi localizado na barriga, porque uma delas, bastante gorda, utilizava um vestido com o desenho de uma mulher magra, com a barriga à mostra.

Esses e vários outros tipos de associação foram desenhados em meu corpo, sem que eu tivesse buscado analisar sua natureza. Após registrar as associações sobre o desenho no papel, marquei todos os pontos de referência no corpo com caneta azul, porque essa, sobre minha pele, pareceu-me mais neutra que qualquer outra cor disponível, e assim, às 20h30, apresentei o trabalho, ligando um ponto a outro pelo traço de uma caneta sobre a pele, o que fazia enquanto relatava as informações dos grupos aos espectadores. A duração da performance foi de 50 minutos.

Refletindo, a posteriori, sobre o uso das imagens extraídas a partir dos blocos de informação e associadas a localidades em meu corpo para a memorização, suspeitei de que elas poderiam ser entendidas como o que os pesquisadores das artes da memória chamaram de imagens agentes, conceito reelaborado por investigadores contemporâneos a partir das traduções do Ad Herennium:

Devemos, portanto, fixar imagens de qualidade tal que adiram o mais longamente possível na memória. E fá- 
lo-emos se fixarmos as aparências as mais extraordinárias; se fixarmos imagens que sejam, não muitas ou vagas, mas eficazes (imagens agentes) (apud ALMEIDA, 1999, p. 51).

Autor do trecho citado, Milton Almeida foi um investigador brasileiro, filiado aos estudos de imagem no cinema e na educação, que se apropriou da proposição das imagens agentes, recorrendo a elas para pensar a arte cinematográfica como uma arte da memória. Sobre a concepção dessa abordagem, relatanos Carlos Miranda, um de seus continuadores:

$O$ apelo de Yates para que o estudo da arte da memória inclua mais do que a história das técnicas mnemônicas e o fato de essa arte valer-se de uma técnica mediante a qual se imprimem na memória "lugares" e "imagens" levou Almeida a imaginar e a perceber relações históricas entre as artes mnemônicas apresentadas por Yates e a moderna e contemporânea arte cinematográfica, permitindo-nos vislumbrar um maravilhoso e fantástico programa visual que estabelece relações entre a construção secular da memória e do olhar e a construção contemporânea da memória e do olhar pelas imagens e palavras em movimento no cinema, conforme citação feita acima (MIRANDA, 2008, p. 108).

Mas que imagens estariam habilitadas a atuarem como imagens agentes? Teriam os mestres da retórica indicações que auxiliassem o aprendiz na seleção dessas imagens? Embora, segundo Yates (2007), os mestres fossem pouco prescritivos e mais orientados a um ensino diligente, tanto o Ad Herennium como os textos deixados por Cícero nos informam que basta observarmos a natureza para sabermos operar esta escolha: quais as imagens de que nos lembramos espontaneamen- te, quando não estamos nos propondo a construir nossa memória artificial? Respondem eles: são as imagens esplêndidas, belíssimas; imagens chocantes; imagens inéditas, de experiências intensas (ALMEIDA, 1999, p. 70). É assim que Almeida proporá a relação entre as imagens do Palácio da Memória e as imagens cinematográficas:

Imagens de catástrofes, imagens fantásticas, imagens violentas e ensanguentadas, imagens de ambientes aristocráticos, nobres, burgueses, pleno de decoração maravilhosa, imagens de seres extra-terrestres, grotescos, híbridos, imagens angelicais, imagens infernais, povoam os afrescos em movimento do cinema. Não somente essas, mas todas as imagens que vemos no cinema, devido ao tamanho enormecido e aos planos de aproximação, o close, por exemplo, em que aparecem na tela são também formas fantásticas. Em todos os gêneros, mesmo em seu gênero "cult, artístico, intelectual" o cinema e, também, a televisão, revelam-se uma arte da memória e seus trajetos originários enlaçam, em um certo momento, o $A d$ Herennium e participam da memória coletiva, histórica. (ALMEIDA, 1999, p. 55-56)

Aproximando tais afirmações da arte, que é a nossa matéria - objeto que é também fundado em imagens - passo a questionar: quais as imagens agentes que a arte da performance pode levar ao seu público? Quais as imagens agentes que a arte da performance informa sobre sua própria história? Seria a arte da performance também uma arte da memória? Como poderia a arte da performance operar, recorrendo às imagens agentes, a (re) criação in situ de sua própria memória (afastando-se da reafirmação de uma memória retentiva)? 
Performances da metalinguagem - fricções com a pesquisa

Arriscando-me à interpretação da obra que elaborei, proponho que Somamnemosis possa ser lida como um "perspectivante historiográfico", na medida em que poderia suscitar reflexões acerca das diferentes escolas históricas que se constituem na abordagem da arte da performance, bem como sobre os modos e instrumentos pelos quais o conhecimento em arte da performance vem sendo produzido através do tempo, destacando o valor do relato de memória na constituição desse projeto. Ou ainda, numa outra possível interpretação, nascida da leitura de todo o processo de composição e apresentação da obra e não apenas do ponto de vista do espectador, proponho que leiamos Somamnemosis como um instrumento para produção de historiografia, entendida essa como o exame dos discursos dos diferentes historiadores (SILVA E SILVA, 2006) - a performance como um método da pesquisa e produção historiográfica baseado em artes.

Entretanto, enquanto a historiografia praticada no campo da disciplina de História teria que, como maior utilidade, segundo Bourdé e Martin, "demonstrar, pela observação dos historiadores passados, que todo historiador sofre pressões ideológicas, políticas e institucionais, comete erros e tem preconceitos" (SILVA E SILVA, 2006, p. 189), constituindo-se como importante "vacina contra a ingenuidade" (idem) a historiografia-performativa-em-arte, aventada por Somamnemosis, questionaria os limites do registro histórico escrito descritivo e a narrativa cronológica dessa arte, seus métodos e a efetividade de suas contribuições para o conhecimento e a prática desta forma.
Ao mesmo tempo, assumiria em absoluto a parcialidade e contextualidade da narrativa dado que o grupo de espectadores é e sabese o grupo respondente - ao invés de buscar negá-la ou suprimi-la.

Essa aproximação do fazer performático com a história e a historiografia somente faz-se possível frente às concepções contemporâneas de História, especialmente aquelas enunciadas como a-científicas, como a chamada Nova História Cultural. A partir do entendimento da História como uma forma de arte, próxima mais da ficção que da ciência, ou ainda, como em White (apud SILVA E SILVA, 2006, p. 189), da História como um gênero da literatura, é que podemos arriscar-nos a pensar as possibilidades de uma obra de arte como fazer historiográfico, num movimento espiralado: história- como-arte-como-história.

Após a apresentação, alguns espectadores procuraram por mim, para contar-me de suas sensações e, especialmente, de lembranças que daquelas e de outras performances o trabalho havia suscitado. Foi o caso, por exemplo, de uma mulher que se lembrou da obra "Desenho-corpo", videoperformance de 2001 da artista paulistana Lia Chaia, em que ela desenha sobre o corpo com uma caneta Bic azul até que a tinta da caneta se acabe (51 minutos). Espectadores que haviam presenciado as ocorrências de algumas das performances relatadas ofereceram-me detalhes que $o$ confronto entre as informações recolhidas na internet e nos livros não me haviam ofertado. Com isso, se reapresentada, a obra contará ainda outras camadas de sentido.

Visando às conclusões, proponho a fricção de nossa questão inicial - quais os limites de afirmarmos uma história da arte da performance - com as questões propostas pela 
obra: quais as implicações ou influências que uma proposição historiográfica performativa em arte pode alcançar?

Certamente, Somamnemosis não carrega ineditismo na proposta de funcionar como instrumento historiográfico ou de debater uma questão teórica pela via do fazer criativo. Diversos trabalhos em arte da performance precedentes já se ofereceram como tomadas de posição metalinguísticas, dentre os quais convém destacar as experiências de Marina Abramovic. Em 1992, a artista iugoslava iniciou tentativas artísticas em performance, visando à permanência de propostas realizadas no passado. Com isso, criou The Biography, espetáculo teatral que reapresentava trabaIhos propostos por ela em momentos anteriores, teatralizando a performance em busca de sua sobrevida, num solo com duração total de uma hora (FORNACIARI, 2010, 2). Na sequência, em 2005, realizou suas Seven Easy Pieces, exposição na sede nova-iorquina do museu Guggenhein em que ela apresentou programas performativos anteriormente realizados por seis artistas, dentre as quais ela figurava, além de uma nova peça. Nesse momento, propôs a noção de reenactment, conformada por um código de conduta que incluía pedir a permissão do artista propositor para realizar a re-encenação, pagar pelos seus direitos autorais e realizar uma nova interpretação da peça - regra que destaca o caráter de memória dinâmica que a artista pretendia para sua proposição (FORNACIARI, 2010, 4). Então, já em 2010, em sua exposição no Museu de Arte Moderna (MoMA), ainda em Nova York, a artista propõe não mais encenações ou reencenações, mas o que chamou de re-performances, reapresentações mais literais da performance original, que inclusive solicitariam aos reperformadores que treinassem para a qualidade da nova presentação próxima à do feitio original (FORNACIARI, 2010, 5).

Os conceitos lançados por Abramovic, quando de suas propostas artístico-conceituais, reverberam amplamente nos campos de pensamento da memória e da história da arte da performance, incitando à reflexão no que concerne a certezas anteriormente estabelecidas, como a irreprodutibilidade e a perecibilidade ou fugacidade desta forma de arte - ou ainda, como preferiria Peggy Phelan, sua "vocação para o esquecimento" (PHELAN,1998).

Uma das reverberações das ações de Abramovic, no debate memória/história da arte da performance, dialoga diretamente com a pedagogia desta arte, abordando mais propriamente as possibilidades do ensino de práticas em arte da performance pela via da re-performação. Posiciono essa ideia, então, ao lado de Somamnemosis, para lançarmos nova luz sobre a proposição desse trabalho, agora em sua relação com minha prática docente. Enquanto performava Somamnemosis, senti que havia um paralelo entre a postura performativa que assumia e aquela a que recorro no momento de ministrar uma aula. Esse processo certamente teve a participação da pretendida memória ativa e re-criadora, que recriou, em mim e em mim-em-performance, traços microperceptivos da performance docente. Teria eu apresentado uma aula de história da arte da performance, uma aula que diferiria das aulas tradicionais pelo seu caráter po(i)ético? Recordo de um material didático que elaborei para a utilização na disciplina de performance, no âmbito do curso de licenciatura em Teatro: uma linha do tempo na plataforma Prezi, que quando apresentada configura-se em algo muito próximo daquilo que apresentei, parcialmente inde- 
pendente da complementação da fala, porém fundado em imagens pretensamente reais, de suposto registro, e desencarnada. Como dar uma aula encarnada de história da arte da performance? Teria eu conseguido? Eu soube que poderia encarnar ainda mais essa história trazendo meu corpo na sua tridimensionalidade, na realização de algumas ações que pudessem ser incorporadas - como a recordada ação de Lia Chaia. Tive o insight ${ }^{1}$ de seguir propondo essa performance, e, ao longo dos eventos, continuar incorporando novas respostas, sem descartar as anteriores, testando os limites da minha memória e da minha técnica de memorização, ampliando os campos contextuais da investigação e problematizando, por meio de novas perspectivas, as questões inicialmente propostas pelo trabalho.

Referências

ALICE, Tânia. O re-enactment como prática artística e pedagógica no Brasil. Disponível em http://hemisphericinstitute.org/hemi/pt/e-misferica-81/alice. Acesso em 09/01/2015

ALMEIDA, Milton José de. Cinema Arte da Memória. Campinas: Autores Associados, 1999.

ASSOCIAÇÃO BRASIL PERFORMANCE. Perfor5 Convocatória. Disponível em http://brasilperformance.blogspot.com.br/2014/09/ perfor5-convocatoria.html. Acesso em 09 de janeiro de 2015.

DIAS, Belidson, IRWIN, Rita L. Pesquisa Edu-

$1 \mathrm{Ou}$, como me foi sugerido pelo professor Wenceslao de OIiveira (FE-UNICAMP) em comentário pessoal à leitura deste texto, talvez trate-se de um outsight - um lance de visão motivado por estímulos exteriores e que se dirige ao exterior. cacional Baseada em Artes: A/R/Tografia. Santa Maria/RS: Editora da UFSM, 2013.

FORNACIARI, Christina. Fazer o novo, fazer de novo? Marina Abramovic e a performance para além do documento. Memória ABRACE - Anais do VI Congresso da Associação Brasileira de Pesquisa e Pós-Graduação em Artes Cênicas. São Paulo: Universidade Estadual de São Paulo e Universidade de São Paulo, 2010.

DELEUZE, Gilles e GUATTARI, Félix. 19951997. Mil Platôs. Capitalismo e Esquizofrenia. Rio de Janeiro: Editora 34. 715 pp.

LEONARDELLI, Patrícia. A memória como recriação do vivido. Um estudo da história do conceito de memória aplicado às artes performativas na perspectiva do depoimento pessoal. Tese de doutorado apresentada ao Programa de Pós-Graduação da Escola de Comunicação e Arte da Universidade de São Paulo - USP, 2008. Disponível em http://www. teses.usp.br/teses/disponiveis/27/27156/tde07052009-143057/pt-br.php. Acesso em 09 de janeiro de 2015.

MIRANDA, Carlos Eduardo Albuquerque. Reflexões de um tempo e diligências para metodologias de estudo de imagens em educação. Educação e Realidade. N. 33, v. 1, jan-jun 2008, p.99-116

PAÇO DAS ARTES. MaPa - Memória Paço das Artes. Disponível em http://www.pacodasartes.org.br/eventos-e-acoes-de-formacao/ lancamento_plataforma_arte_contemporanea. aspx. Acesso em 09 de janeiro de 2015.

PASSOS, Eduardo; KASTRUP, Virgínia; ES- 
CÓSSIA, Liliana da. Pistas do método da cartografia - pesquisa-intervenção e produção de subjetividade. Porto Alegre: Sulina, 2009.

PHELAN, Peggy. A ontologia da performance. Revista de Comunicação e Linguagens; nr. 24, Editora Cosmos: Lisboa, 1998.

RIBEIRO, Fernando. Performance art e filosofia. Disponível em http://www.fernandoribeiro. art.br/br/outros/artigos/item/42-performance-art-e-filosofia. Acesso em 09/01/2015...

SILVA, Kalina Vanderlei e SILVA, Maciel Henrique. Dicionário de conceitos históricos. São Paulo: Contexto, 2006.

YATES, Frances Amelia. A arte da memória. Campinas: Editora da UNICAMP, 2007.

Recebido em: 31/03/2016 Aprovado em: 25/10/2016 